\title{
Studies on Electric and Dielectric Properties of Porous $\mathrm{Sm}_{0.5} \mathrm{Sr}_{0.5} \mathrm{CoO}_{3-\delta}$
}

\author{
S. S. Pawar, ${ }^{1}$ K. P. Shinde, ${ }^{2}$ A. G. Bhosale, ${ }^{1}$ and S. H. Pawar ${ }^{1,3}$ \\ ${ }^{1}$ Department of Physics, Shivaji University, Kolhapur 416 004, India \\ ${ }^{2}$ Korea Electrothechnology Research Institute, Changwon, Republic of Korea \\ ${ }^{3}$ Center for Interdisciplinary Research, D. Y. Patil University, Kolhapur, India
}

Correspondence should be addressed to S. S. Pawar; sspawar.phy@gmail.com

Received 19 November 2012; Revised 7 March 2013; Accepted 7 March 2013

Academic Editor: Roland Frankenberger

Copyright (C) 2013 S. S. Pawar et al. This is an open access article distributed under the Creative Commons Attribution License, which permits unrestricted use, distribution, and reproduction in any medium, provided the original work is properly cited.

\begin{abstract}
Frequency-dependent electric and dielectric properties of the porous $\mathrm{Sm}_{0.5} \mathrm{Sr}_{0.5} \mathrm{CoO}_{3-\delta}$ cathode prepared through conventional combustion synthesis technique were studied in the temperature range $298 \mathrm{~K}-973 \mathrm{~K}$. The crystal symmetry, space group, and unit cell dimensions were confirmed by analyzing XRD pattern. XRD analysis indicates the formation of a single-phase orthorhombic structure with space group Pnma 62. Scanning electron microscopy technique was used to examine the morphology of the sample. Scanning electron microscopy study showed the formation of porous structure with an average grain size about $850 \mathrm{~nm}$. From the electrical study, it is observed that the conduction in $\mathrm{Sm}_{0.5} \mathrm{Sr}_{0.5} \mathrm{CoO}_{3-\delta}$ sample takes place through the hopping mechanism and follows the inverse universal power law. The correlated barrier hopping model was employed successfully to explain the mechanism of charge transport in $\mathrm{Sm}_{0.5} \mathrm{Sr}_{0.5} \mathrm{CoO}_{3-\delta}$. Further, the ac conductivity data was used to evaluate the minimum hopping length and apparent activation energy. The minimum hopping length was found to be $\sim 10^{-4}$ times smaller than the grain size of $\mathrm{Sm}_{0.5} \mathrm{Sr}_{0.5} \mathrm{CoO}_{3-\delta}$. The peaking behaviour of the real part of dielectric constant with frequency was explained using the Rezlescu model. This study helps to confirm that the charge transportation in $\mathrm{Sm}_{0.5} \mathrm{Sr}_{0.5} \mathrm{CoO}_{3-\delta}$ is due to two types of charge carriers.
\end{abstract}

\section{Introduction}

Recent worldwide interest in building a decentralized, hydrogen-based energy economy has refocused attention on the solid oxide fuel cell (SOFC) as a potential source of efficient, environmental friendly, fuel-versatile electric power generation $[1,2]$. Performance of the solid oxide fuel cell mostly depends on properties of the electrolyte, anode, and cathode materials. From the last 20 years, scientific community is trying to understand the SOFC materials in terms of their chemical, thermal, catalytic, structural, morphological, and transport properties and their effect on performance of solid oxide fuel cell [3-6].

Recently, strontium-doped samarium cobaltate, $\mathrm{Sm}_{0.5} \mathrm{Sr}_{0.5} \mathrm{CoO}_{3-\delta}$ (SSC), with $x=0.5$ is being investigated as a cathode material to replace the conventional $\mathrm{La}_{1-x}$ $\mathrm{Sr}_{x} \mathrm{MnO}_{3-x}$ (LSM) material. This is due to the high catalytic activity of SSC for the oxygen reduction reaction (ORR) as well as its excellent ionic and electronic conductivity over a wide range of temperatures. SSC has a compatible thermal expansion coefficient (TEC) with ceria-based electrolytes, which possess the higher ionic conductivity at lower temperatures [7-12]. The study of electrical transport properties in cathode is very important since the associated catalytic properties are dependent on the nature and magnitude of conductivity in these materials. An extensive literature survey suggests that no attempt has been made to understand the charge transportation in SSC with frequency.

A diversity of scientific disciplines endeavour to understand dynamic processes and conduction mechanism by examining the ac response of materials to an applied time varying electric field. One strategy for understanding the cathode performance is to know the charge transport mechanism with the temperature and frequency [13]. Recently, frequency domain study of the material in desired temperature range is used to gaze inside the material [14]. The study of this dispersive behaviour offers an opportunity to gain insight 
into the details of electronic/ionic migration processes, particularly the interaction of the migrating electrons/ions with other defects in the structure [15].

In the present investigation, for the first time we are reporting the frequency response measurement of $\mathrm{Sm}_{0.5} \mathrm{Sr}_{0.5} \mathrm{CoO}_{3-\delta}$ over the temperature range $298 \mathrm{~K}-973 \mathrm{~K}$ in terms of ac conductivity and complex permittivity. The correlated barrier hopping model has been used to assert the conduction mechanism in the system. The ac conductivity data have been used to estimate the apparent activation energy and minimum hopping length. Further, the dielectric data has been explained in the light of Rezlescu model to understand the charge transportation.

\section{Experimental}

Phase pure $\mathrm{Sm}_{0.5} \mathrm{Sr}_{0.5} \mathrm{CoO}_{3}$ sample was prepared by selfpropagating combustion synthesis method using polyvinyl alcohol as an efficient fuel for combustion. High-purity $\mathrm{Sm}_{2} \mathrm{O}_{3}, \mathrm{Sr}\left(\mathrm{NO}_{3}\right)_{2}, \mathrm{Co}\left(\mathrm{NO}_{3}\right)_{2} \cdot 6 \mathrm{H}_{2} \mathrm{O}$ all from Loba Chemie were used as an oxidizer and poly-vinyl alcohol as a fuel. The stoichiometric composition of the redox mixtures for combustion was calculated using the total oxidizing $(\mathrm{O})$ and reducing $(\mathrm{R})$ valences of components which served as the numerical coefficients for the stoichiometric balance, so that equivalence ratio was a unity (i.e., $\mathrm{O} / \mathrm{R}=1$ ), and energy released by the combustion was maximum [16].

The overall combustion reaction for SSC can be represented as follows:

$$
\begin{aligned}
0.5 \mathrm{Sm}\left(\mathrm{NO}_{3}\right)_{3} & +0.5 \mathrm{Sr}\left(\mathrm{NO}_{3}\right)_{2}+\mathrm{Co}\left(\mathrm{NO}_{3}\right)_{2} \\
& +2.25\left(\mathrm{C}_{2} \mathrm{H}_{4}-\mathrm{O}\right)+0.375 \mathrm{O}_{2} \\
& \longrightarrow \mathrm{Sm}_{0.5} \mathrm{Sr}_{0.5} \mathrm{CoO}_{3}+4.5 \mathrm{CO}_{2} \uparrow \\
& +4.5 \mathrm{H}_{2} \mathrm{O} \uparrow+2.25 \mathrm{~N}_{2} \uparrow
\end{aligned}
$$

This charred powder was pressed under the load of 10 ton $/ \mathrm{cm}^{2}$ into circular pellets using German-made hydraulic press and PVA as a binder. The pellet thus formed was kept in the muffle furnace at $1000^{\circ} \mathrm{C}$ for two hours.

$\mathrm{X}$-ray diffraction (XRD) pattern of the sample is taken at room temperature using Philips diffracto-meter (PW 1710) with $\mathrm{Cu} \mathrm{K} \alpha$ radiation over a wide range of Braggs angle $\left(10^{\circ}-90^{\circ}\right)$. The morphological evolution was carried out using scanning electron microscope (SEM JEOL JSM 6360). To study the electrical properties, both flat surfaces of the pellet pellets were painted with fine silver paste as electrode and were kept at $350^{\circ} \mathrm{C}$ for one hour. The ac conductivity and dielectric measurements were carried out with frequency $(10 \mathrm{~Hz}$ to $20 \mathrm{MHz}$ ) and at temperatures $298 \mathrm{~K}$ to $973 \mathrm{~K}$ using computer controlled impedance analyzer (Nova Control, Alpha-N, Germany). The temperature was controlled with the programmable oven.

\section{Results and Discussion}

3.1. Structural Study. Figure 1 shows the XRD pattern of $\mathrm{Sm}_{0.5} \mathrm{Sr}_{0.5} \mathrm{CoO}_{3-\delta}$ sample heat treated at $1000^{\circ} \mathrm{C}$. All the

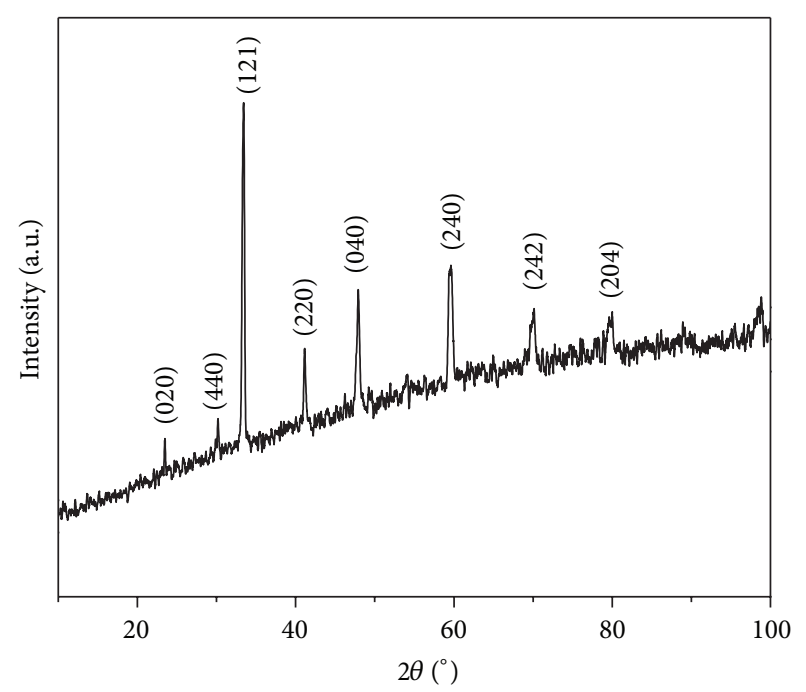

FIgURE 1: X-ray diffraction pattern of $\mathrm{Sm}_{0.5} \mathrm{Sr}_{0.5} \mathrm{CoO}_{3-\delta}$ sample.

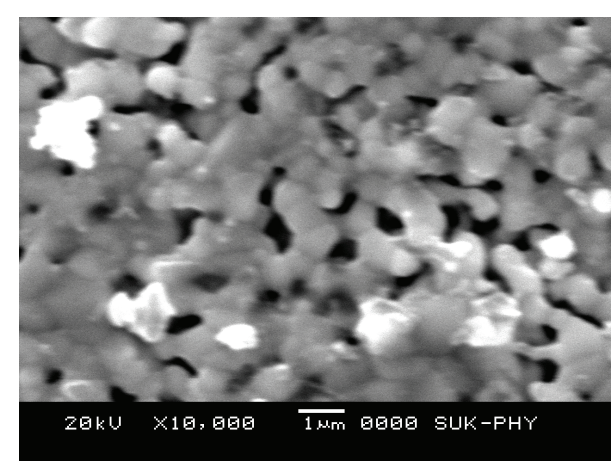

FIGURE 2: SEM micrograph of the $\mathrm{Sm}_{0.5} \mathrm{Sr}_{0.5} \mathrm{CoO}_{3-\delta}$ sample.

high-intensity reflections in this sample are identical with earlier reported orthorhombic $\mathrm{Sm}_{0.5} \mathrm{Sr}_{0.5} \mathrm{CoO}_{3-\delta}$ phase. The calculated lattice parameters $(a=5.39 \AA, b=7.59 \AA$, and $c=5.30 \AA$ ) were found to be in good agreement with earlier reported values (JCPDS card no. 00-053-0112). The good agreement between observed Braggs angle and interplanar spacing values with JCPDS card values shows the formation perovskite phase-pure $\mathrm{Sm}_{0.5} \mathrm{Sr}_{0.5} \mathrm{CoO}_{3-\delta}$.

3.2. Morphological Study. Figure 2 shows the micrograph of the SSC sample heat treated at $1000^{\circ} \mathrm{C}$. Formation of porous morphology with $3 \mathrm{D}$ grain connectivity is developed which is the key property of the cathode order to facilitate the sites for oxygen reduction $[7,17]$. This type of morphology had made it possible mainly because of the key role played by residual carbon and PVA added during pelletization. The exothermic reaction of carbon with oxygen results in formation of gas channels and voids in the sample. Further heat treatment exerts pressure on interior walls of gas channels and voids, and at critical stage this pressure breaks the septum between these channels and voids which leads to formation of porous structure with well grain connectivity. This $3 \mathrm{D}$-connected porous network will give possible free path for electrons and 
oxygen ions within porous structure. The average grain size of the SSC sample was calculated by using Image-J analysis software. The average grain size is about $850 \mathrm{~nm}$, which is quite higher than the mean free path of the charge carriers. This large difference in mean free path and average grain size suggests that the conductivity of the SSC sample is limited by the intragrain charge transportation process.

3.3. Conductivity Study. The conductivity representation is most prominent delegacy to relate macroscopic measurements and microscopic movements of the charge carriers. Figure 3 shows the log-log plot of ac electrical conductivity $\left(\sigma_{\mathrm{ac}}\right)$ versus frequency at different temperatures. The plot of $\sigma_{\mathrm{ac}}$ shows a frequency-independent region in the lowfrequency region, followed by a region that is sensitive to the frequency as well as temperature. The frequency independent conductivity characterizes the dc conductivity, due to the random diffusion of the charge carriers via activated hopping. However, the frequency-dependent region indicates a nonrandom process, wherein the ions perform correlated forward-backward motion. The switch from the frequency independent to the frequency-dependent regions shows the onset of the conductivity relaxation phenomenon which indicates the translation from long-range hopping to the shortrange cluster motion [18]. Further, the electrical conductivity of the materials due to localized states is expressed as a power law $[19,20]$ :

$$
\sigma_{\mathrm{ac}}(\omega)=\sigma(0)+\sigma^{\prime}(\omega),
$$

where $\sigma(0)$ and $\sigma^{\prime}(\omega)$ are the frequency-independent and frequency-dependent parts of the conductivity, respectively. The conductivity of the SSC sample decreases with increase in the frequency in high-frequency region. In this frequency region the applied field obstructs hopping conduction process which leads to decrease in the overall conductivity. Also, $\sigma^{\prime}(\omega)$, found to obey universal behaviour in the frequency sensitive region as follows:

$$
\sigma^{\prime}(\omega)=A \omega^{s},
$$

where $s(0 \leq s \leq 1)$ is the index, $\omega$ is angular frequency of the applied ac field, $A\left[=\pi N^{2} e^{2} / 6 k_{B} T(2 \alpha)\right]$ is a constant, $e$ is the electronic charge, $T$ is temperature, $\alpha$ is polarizability of a pair of site, and $N$ is the number of sites per unit volume in which hopping takes place. Such variation is associated with displacement of carriers which move within the sample by discrete hops of length $R$ between randomly distributed localized sites. The term $A \omega^{s}$ can be explained by two distinct mechanisms for carrier conduction: quantum mechanical tunnelling (QMT) through the barrier separating the localized sites and correlated barrier hopping $(\mathrm{CBH})$ over the same barrier. In these models, the exponent $s$ is found to have two different trends with temperature and frequency. If the ac conductivity is originated from QMT, $s$ is predicted to be temperature independent but expected to show a decreasing trend with $\omega$, while for $\mathrm{CBH}$, temperature dependence of $s$ should show a decreasing trend [18]. The values of the index " $s$ " were obtained from the slopes of the

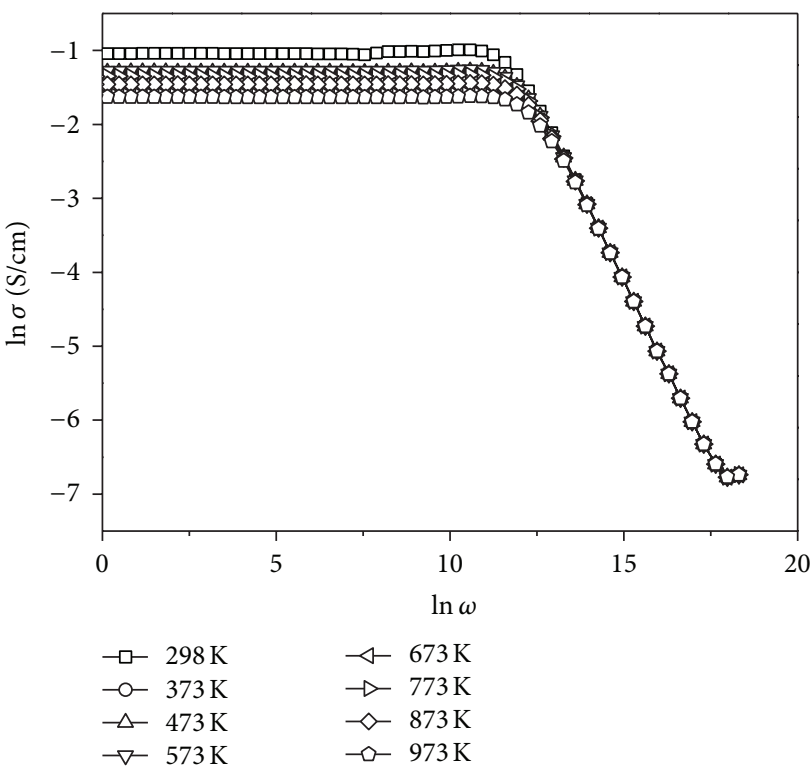

FIGURE 3: Log-log plot of electrical conductivity versus angular frequency for $\mathrm{Sm}_{0.5} \mathrm{Sr}_{0.5} \mathrm{CoO}_{3-\delta}$ sample at different temperatures.

plots in the high-frequency region. From Figure 4 it is seen that value of " $s$ " decreases with increasing the temperature which predicts that the correlated barrier hopping is the dominating conduction mechanism in SSC sample.

The conduction in $\mathrm{Sm}_{0.5} \mathrm{Sr}_{0.5} \mathrm{CoO}_{3-\delta}$ is a consequence of $\mathrm{Sr}$ doping in $\mathrm{SmCoO}_{3}$, in which charge imbalance is compensated by the formation of oxygen ion vacancies or holes. These compensations can be explained with the help of following equations.

For compensation by oxygen ion vacancies,

$$
2 \mathrm{SrO}\left(\mathrm{SmCoO}_{3} \longrightarrow 2 \mathrm{Sr}_{\mathrm{Sm}}^{\prime}+2 \mathrm{O}_{\mathrm{o}}^{x}+\mathrm{V}_{\mathrm{o}}^{*}\right.
$$

and the compensation by holes

$$
\mathrm{SrO}\left(\mathrm{SmCoO}_{3}\right) \longrightarrow \mathrm{Sr}_{\mathrm{Sm}}^{\prime}+\mathrm{Co}_{\mathrm{Co}}^{\circ}+\mathrm{O}_{\mathrm{o}}^{x}
$$

The possibilities that the holes are localized on Co atom are reasonable,

$$
\mathrm{Co}+\mathrm{h}^{*} \longrightarrow \mathrm{Co}^{*}
$$

that is,

$$
\mathrm{Sr}\left(\mathrm{SmCoO}_{3}\right)+\frac{1}{2} \mathrm{O}_{2} \longrightarrow \mathrm{Sr}_{\mathrm{Sm}}^{\prime}+\mathrm{Co}^{*}+4 \mathrm{O}
$$

Thus, (5) and (7) show that the conduction in the $\mathrm{Sm}_{0.5} \mathrm{Sr}_{0.5} \mathrm{CoO}_{3-\delta}$ is a consequence of contribution due to the hopping of holes and oxygen ion vacancies [21].

During conduction, these charge carriers facilitate the appearance of diploes formed with an adjacent host ion and enlarge the ratting space available for dipole vibration, which as a consequence leaded to the short-range hopping of the charge carriers and gave rise to the hopping type of relaxation. Using correlated barrier hopping $(\mathrm{CBH})$ model 


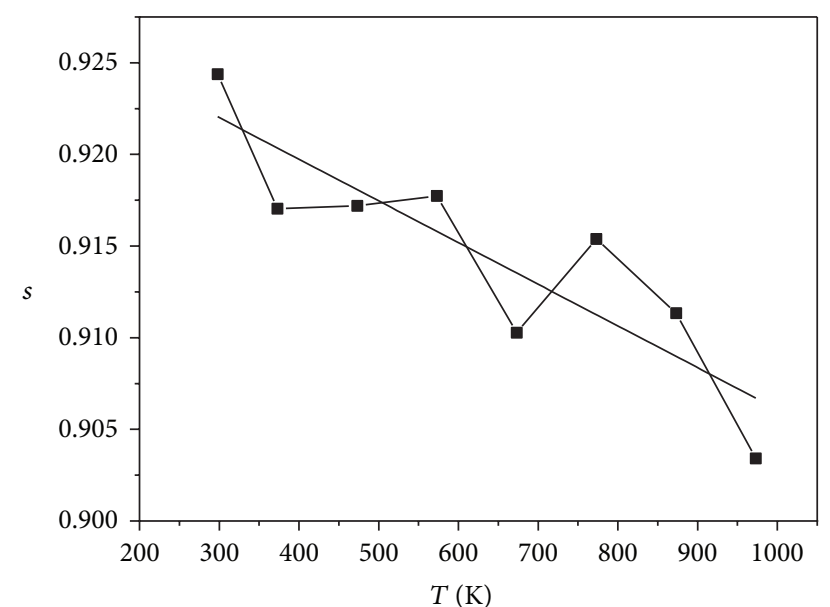

FIGURE 4: Temperature-dependent variation in exponent " $s$ " for $\mathrm{Sm}_{0.5} \mathrm{Sr}_{0.5} \mathrm{CoO}_{3-\delta}$ sample.

[17], the binding energy can be calculated using following equation:

$$
s=1-\beta,
$$

where

$$
\beta=\frac{6 k_{B} T}{W_{m}},
$$

and $W_{m}$ is the binding energy, which is defined as the energy required to remove a charge carrier completely from one site to another site. The binding energy $W_{m}$ is calculated by using (8). Using the values of the binding energy minimum hopping distance $\left(R_{\min }\right)$ can be calculated as follows [22]:

$$
R_{\min }=\frac{2 e^{2}}{\pi \varepsilon_{0} \varepsilon W_{m}},
$$

where $\varepsilon_{o}$ is the permittivity of the free space. The minimum hopping length $\left(R_{\min }\right)$ versus angular frequency was studied for different temperatures to analyze the effect of temperature on the cluster motion. The angular frequency dependence of $R_{\min }$ at different temperatures is shown in Figure 5. From this figure it is seen that $R_{\min }$ increases with the increase in the frequency. Such observations may possibly be related to restoring force governing the mobility of charge carriers under the action of an induced electric field. This behaviour supports long-range mobility of charge carriers. The temperaturedependent variation in $R_{\min }$ shows that (Figure 5 ) the values of $R_{\min }$ decrease with the increase in temperature. This indicates that the increase in temperature may be attributed to the conduction phenomena due to short-range mobility of charge carriers. The room temperature value of $R_{\min }$ was found to be of the order of $10^{-10} \mathrm{~m}$ at $1 \mathrm{kHz}$. Also, $R_{\min }$ was found to be $\sim 10^{-4}$ times smaller than the grain size of SSC. This leads to the decrease in overall conductivity of the sample which is low as compare to the reported value [23].

3.4. Dielectric Study. The frequency-dependent real part $\left(\varepsilon^{\prime}\right)$ of dielectric permittivity for SSC at various temperatures is

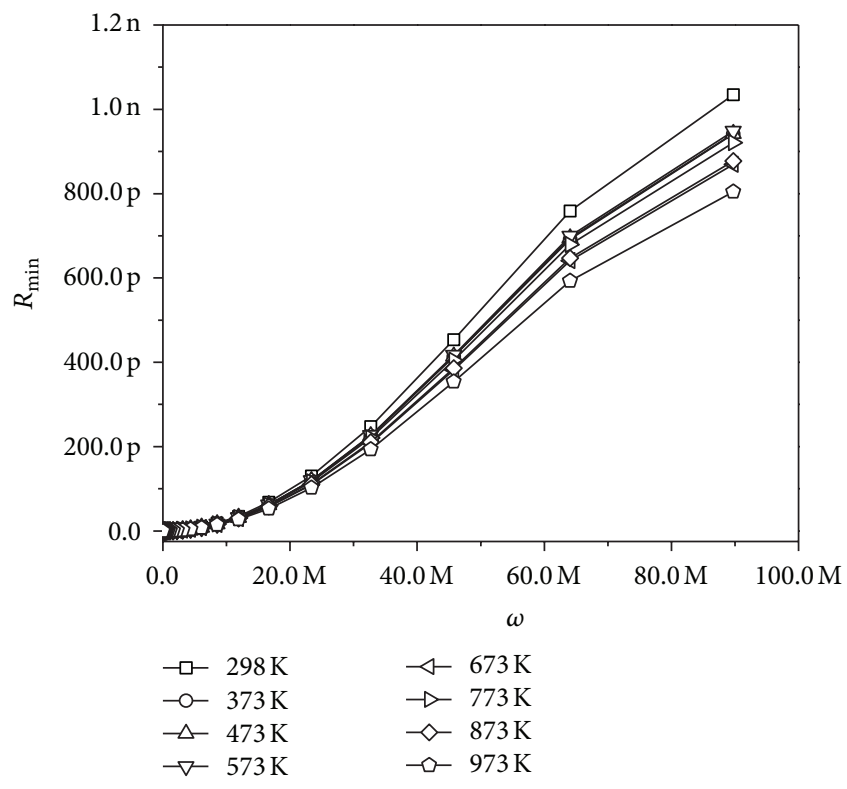

FIGURE 5: Angular frequency dependence of $R_{\min }$ for $\mathrm{Sm}_{0.5} \mathrm{Sr}_{0.5} \mathrm{CoO}_{3-\delta}$ sample at different temperature.

shown in Figure 6. Real part $\left(\varepsilon^{\prime}\right)$ of dielectric permittivity varies negatively with frequency. This may be due to the increase in localised defect states that cause more injected carriers to reside in the localised defect states and contribute to the establishment of built-in electric field. Under an applied field, some of the charge carriers may detrap and can hop along the field direction. Because certain time is needed for carriers to escape from their trap's states, this makes the current induced by the detrapping carrier's lags behind the applied electric field, thereby causing inductive effects [24]. The hopping motion of the detrapped carrier not only give rise to hopping conductivity but also creates dipolar effects.

From Figure 6, it is further noted that there are two peaks observed near $55.99 \mathrm{~Hz}$ and $8.711 \mathrm{kHz}$ frequencies. The peaking behaviour of real part of dielectric constant $\left(\varepsilon^{\prime}\right)$ with $\log$ of angular frequency $(\ln \omega)$ can be explained using Rezlescu model [25]. According to this model, peaks in $\varepsilon^{\prime}(\omega)$ curves can be ascribed to the presences of collective contribution to the polarization from two different types of charge carriers; $[25,26]$ for the sample under investigation, the conduction process can be attributed to the presence of two types of charge carriers, that is, $\mathrm{p}$ type, as a hole exchange between $\mathrm{Co}^{3+}$ and $\mathrm{Co}^{4+}$ and transfer of $\mathrm{O}^{2-}$ between filled side with vacant oxygen side. The following relation-can represent these two mechanisms as follows:

$$
\begin{aligned}
& \mathrm{Co}^{4+} \longrightarrow \mathrm{Co}^{3+}+\mathrm{h}^{*} \\
& \frac{1}{2} \mathrm{O}_{2}+\mathrm{V}_{\mathrm{o}}^{2 *} \longrightarrow \mathrm{O}^{2-}
\end{aligned}
$$

Since the direction of the displacement of holes and oxygen ions is opposite under the application of electric field, the mobility of oxygen ions is relatively very small with respect to that of holes. The resultant polarization of both types of 


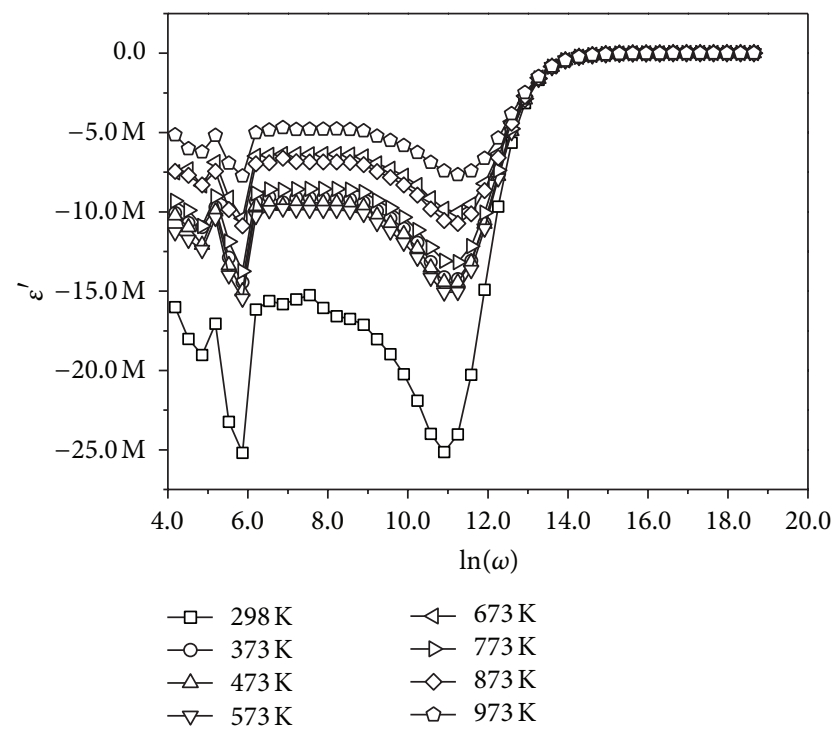

FIGURE 6: Log angular frequency-dependent variation in real part $\left(\varepsilon^{\prime}\right)$ of dielectric permittivity for $\mathrm{Sm}_{0.5} \mathrm{Sr}_{0.5} \mathrm{CoO}_{3-\delta}$ sample at different temperatures.

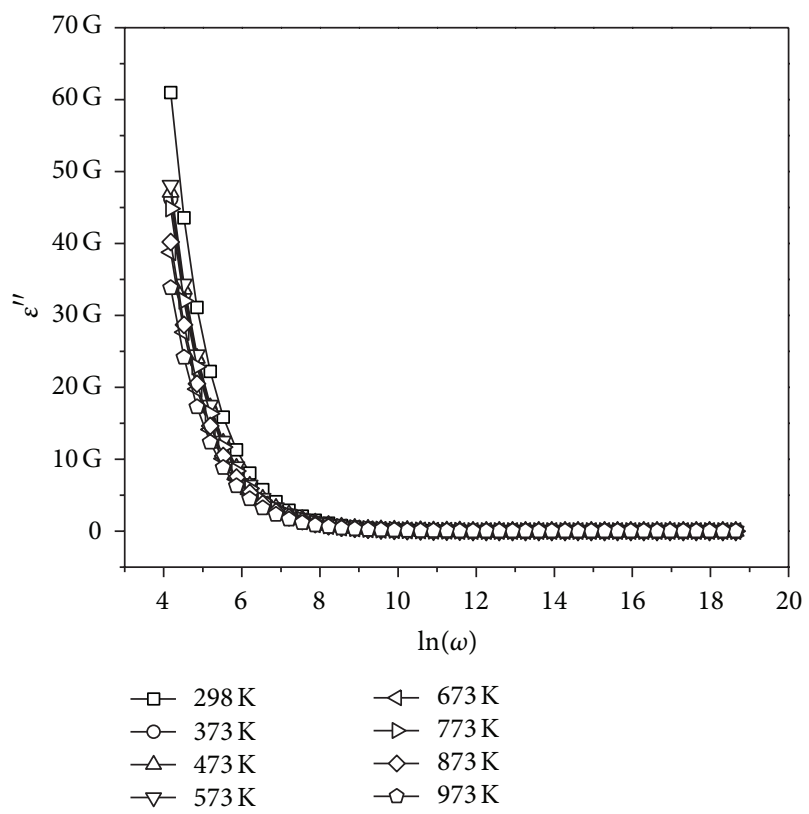

FIGURE 7: Log angular frequency-dependent variation in dielectric loss $\left(\varepsilon^{\prime \prime}\right)$ for $\mathrm{Sm}_{0.5} \mathrm{Sr}_{0.5} \mathrm{CoO}_{3-\delta}$ sample at different temperatures.

charges gives peaking behaviour. The shift of peak towards higher frequency region with increasing temperature may be attributed to the corresponding increase in mobility of the charge carriers. Observation regarding the depth of peak corresponds to the difference in the contribution from the charge carriers, which decreases with increasing temperature. In Figure 6, there is small peak towards the lower frequency side which may be due to the minor charge carriers (electrons).

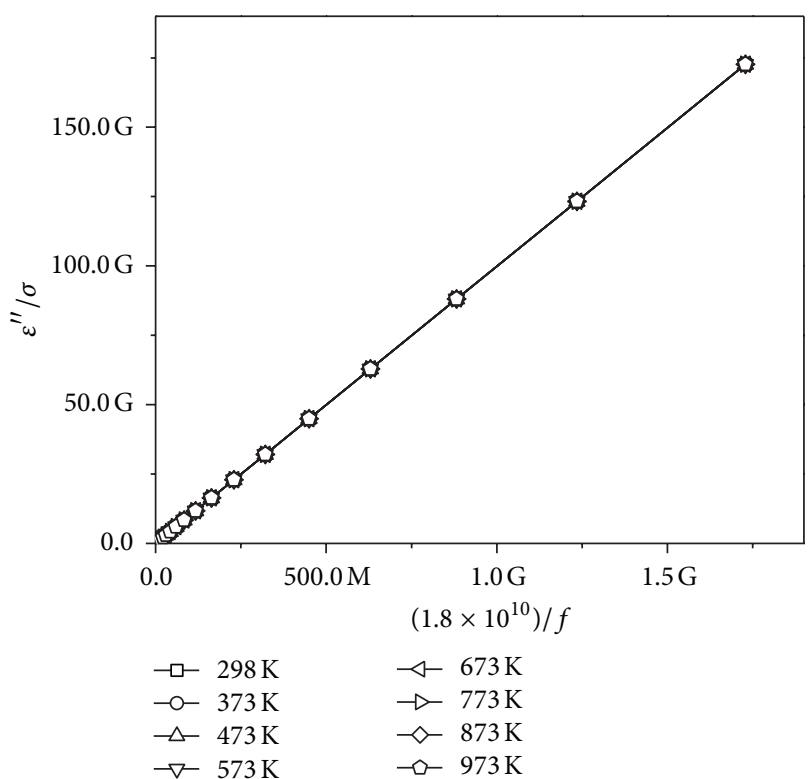

FIGURE 8: Variation in $\left(\varepsilon^{\prime \prime} / \sigma\right)$ with $\left(1.8 \times 10^{10}\right) / f$ in $\mathrm{Sm}_{0.5} \mathrm{Sr}_{0.5} \mathrm{CoO}_{3-\delta}$ sample.

Figure 7 shows the temperature dependence of dielectric loss $\left(\varepsilon^{\prime \prime}\right)$ as a function of frequency for SSC sample. The dielectric loss is rather high at lower frequency but falls quickly with rising frequency and remains frequency independent and follows the Smith and Wijn [27] relation for the same temperature; that is, the ratio between the dielectric loss to the ac conductivity is inversely proportional to the applied frequency. And this can be represented by the following equation:

$$
\frac{\varepsilon^{\prime \prime}}{\sigma}=1.8 \times 10^{10} \times \frac{1}{f} .
$$

In Figure 8 , the plot of $\left(\varepsilon^{\prime \prime} / \sigma\right)$ versus $\left(1.8 \times 10^{10}\right) / f$ gives straight line for SSC sample which confirms the relation given in (12).

As the temperature increase conductivity decreases, and so conduction losses decreases. This decreases the value of $\varepsilon^{\prime \prime}$ with increasing temperature.

\section{Summary and Conclusions}

In summary, the hopping type conduction and dielectric phenomenon has been investigated systematically in SSC sample for first time. The ac conductivity is found to obey the inverse universal power law. The pair approximation type-correlated barrier hopping ( $\mathrm{CHB}$ ) model is found to successfully explain the universal behaviour of the exponent " $s$." Frequency dependence negative variation in real part $\left(\varepsilon^{\prime}\right)$ of dielectric permittivity is linked with the inductive effect, which was found to arise from the hopping motions of the detrapped carriers that also create dipolar effect. A frequency domain measurement of dielectric permittivity and dielectric loss shows that the parameter both decreases 
with the increase in frequency and remains constant in highfrequency region.

\section{Acknowledgments}

The financial support from the Defense Research and Development Organization (DRDO) is gratefully acknowledged. Authors are thankful to Dr. Rajeev Joshi, IISc, Bangalore for fruitful discussion.

\section{References}

[1] M. Kuhn and T. W. Napporn, "Single-Chamber solid oxide fuel cell technology-from its origins to today's state of the art," Energies, vol. 3, no. 1, pp. 57-134, 2010.

[2] M. Yano, A. Tomita, M. Sano, and T. Hibino, "Recent advances in single-chamber solid oxide fuel cells: a review," Solid State Ionics, vol. 177, no. 39-40, pp. 3351-3359, 2007.

[3] T.-L. Wen, D. Wang, M. Chen et al., "Material research for planar SOFC stack," Solid State Ionics, vol. 148, no. 3-4, pp. 513519, 2002.

[4] J. Molenda, K. Świerczek, and W. Zajac, "Functional materials for the IT-SOFC," Journal of Power Sources, vol. 173, no. 2, pp. 657-670, 2007.

[5] J. Rossmeisl and W. G. Bessler, "Trends in catalytic activity for SOFC anode materials," Solid State Ionics, vol. 178, no. 31-32, pp. 1694-1700, 2008.

[6] B. Morel, R. Roberge, S. Savoie, T. W. Napporn, and M. Meunier, "Catalytic activity and performance of LSM cathode materials in single chamber SOFC," Applied Catalysis A, vol. 323, pp. 181187, 2007.

[7] S. B. Adler, "Factors governing oxygen reduction in solid oxide fuel cell cathodes," Chemical Reviews, vol. 104, no. 10, pp. 47914843, 2004.

[8] C. Xia, W. Rauch, F. Chen, and M. Liu, " $\mathrm{Sm}_{0.5} \mathrm{Sr}_{0.5} \mathrm{CoO}_{3}$ cathodes for low-temperature SOFCs," Solid State Ionics, vol. 149, no. 1-2, pp. 11-19, 2002.

[9] J. M. Ralph, C. Rossilgnol, and R. Kumar, "Cathode materials for reduced-temperature SOFCs," Journal of The Electrochemical Society, vol. 150, no. 11, pp. A1518-A1522, 2003.

[10] T. Wu, Y. Zhao, R. Peng, and C. Xia, "Nano-sized $\mathrm{Sm}_{0.5}$ $\mathrm{Sr}_{0.5} \mathrm{CoO}_{3-\delta}$ as the cathode for solid oxide fuel cells with protonconducting electrolytes of $\mathrm{BaCe}_{0.8} \mathrm{Sm}_{0.2} \mathrm{O}_{2.9}$, Electrochimica Acta, vol. 54, no. 21, pp. 4888-4892, 2009.

[11] S. W. Baek, J. H. Kim, and J. Bae, "Characteristics of $\mathrm{ABO}_{3}$ and $\mathrm{A}_{2} \mathrm{BO}_{4}(\mathrm{~A}=\mathrm{Sm}, \mathrm{Sr} ; \mathrm{B}=\mathrm{Co}, \mathrm{Fe}, \mathrm{Ni})$ samarium oxide system as cathode materials for intermediate temperature-operating solid oxide fuel cell," Solid State Ionics, vol. 179, no. 27-32, pp. 1570$1574,2008$.

[12] S. W. Baek, J. Bae, and Y. S. Yoo, "Cathode reaction mechanism of porous-structured $\mathrm{Sm}_{0.5} \mathrm{Sr}_{0.5} \mathrm{CoO}_{3-\delta}$ and $\mathrm{Sm}_{0.5} \mathrm{Sr}_{0.5} \mathrm{CoO}_{3-\delta}$ / $\mathrm{Sm}_{0.2} \mathrm{Ce}_{0.8} \mathrm{O}_{1.9}$ for solid oxide fuel cells," Journal of Power Sources, vol. 193, no. 2, pp. 431-440, 2009.

[13] Y. Li, R. Gemmena, and X. Liua, "Oxygen reduction and transportation mechanisms in solid oxide fuel cell cathodes," Journal of Power Sources, vol. 195, no. 11, pp. 3345-3358, 2010.

[14] A. S. Nowick, A. V. Vaysleyb, and I. Kuskovsky, "Universal dielectric response of variously doped $\mathrm{CeO}_{2}$ ionically conducting ceramics," Physical Review B, vol. 58, no. 13, pp. 8398-8406, 1998.
[15] R. Hui, C. Sun, S. Yick et al., " $\mathrm{Ba}_{1-x} \mathrm{Pr}_{x} \mathrm{Co}_{1-y} \mathrm{FeyO}_{1-\delta}$ as cathode materials for low temperature solid oxide fuel cells," Electrochimica Acta, vol. 55, no. 16, pp. 4772-4775, 2010.

[16] S. R. Jain, K. C. Adiga, and V. R. Pai Verneker, "A new approach to thermochemical calculations of condensed fuel-oxidizer mixtures," Combustion and Flame, vol. 40, no. C, pp. 71-79, 1981.

[17] S. Mollah, K. K. Som, K. Bose, and B. K. Chaudhuri, "AC conductivity in $\mathrm{Bi}_{4} \mathrm{Sr}_{3} \mathrm{Ca}_{3} \mathrm{Cu}_{y} \mathrm{O}_{x}(\mathrm{y}=0-5)$ and $\mathrm{Bi}_{4} \mathrm{Sr}_{3} \mathrm{Ca}_{3-z}$ $\mathrm{Li}_{z} \mathrm{Cu}_{4} \mathrm{O}_{x}(\mathrm{z}=0.1-1.0)$ semiconducting oxide glasses," J. Appl. Phys, vol. 74, no. 2, article 931, 7 pages, 1993.

[18] K. Prasad, Lily, K. Kumari, and K. L. Yadav, "Hopping type of conduction in $\left(\mathrm{Na}_{0.5} \mathrm{Bi}_{0.5}\right) \mathrm{ZrO}_{3}$ ceramic," Journal of Physics and Chemistry of Solids, vol. 68, no. 8, pp. 1508-1514, 2007.

[19] A. K. Jonscher, "The "Universal" Dielectric response," Nature, vol. 267, pp. 673-679, 1977.

[20] R. M. Hill and A. K. Jonscher, "DC and AC conductivity in hopping electronic system," Journal of Non-Crystalline Solids, vol. 32, no. 1-3, pp. 53-69, 1979.

[21] M. Kuznecov, P. Otschik, N. Trofimenko, and K. Eichler, "Oxygen transport in the SOFC cathode," Russian Journal of Electrochemistry, vol. 40, no. 11, pp. 1162-1169, 2004.

[22] R. Salam, "Trapping parameters of electronic defectes states in indium tin oxide from AC conductivity," Physica Status Solidi A, vol. 117, no. 2, pp. 535-540, 1990.

[23] H. Y. Tu, Y. Takeda, N. Imanishi, and O. Yamamoto, " $\operatorname{Ln}_{1-x}$ $\mathrm{Sr}_{x} \mathrm{CoO}_{3}(\mathrm{Ln}=\mathrm{Sm}, \mathrm{Dy})$ for the electrode of solid oxide fuel cells," Solid State Ionics, vol. 100, no. 3-4, pp. 283-288, 1997.

[24] C. C. Wang, G. Z. Liu, M. He, and H. B. Lu, "Low- frequency negative capacitance in $\mathrm{La}_{0 . / 8} \mathrm{Sr}_{0.2} \mathrm{MnO}_{3} / \mathrm{Nb}$-doped $\mathrm{SrTiO}_{3}$ herterojunction," Applied Physics Letters, vol. 92, Article ID 052905, 3 pages, 2008.

[25] N. Rezlescu and E. Rezlescu, "Abnormal dielectric behaviour of copper containing ferrites," Solid State Communications, vol. 14, no. 1, pp. 69-72, 1974.

[26] H. M. Zaki, "AC conductivity and frequency dependence of the dielectric properties for copper doped magnetite," Physica $B$, vol. 363, no. 1-4, pp. 232-244, 2005.

[27] J. Smith and H. P. Wijn, Ferrites: Physical Properties of Ferromagnetic Oxides in Relation to Their Technical Applications, Wiley, New York, NY, USA, 1959. 

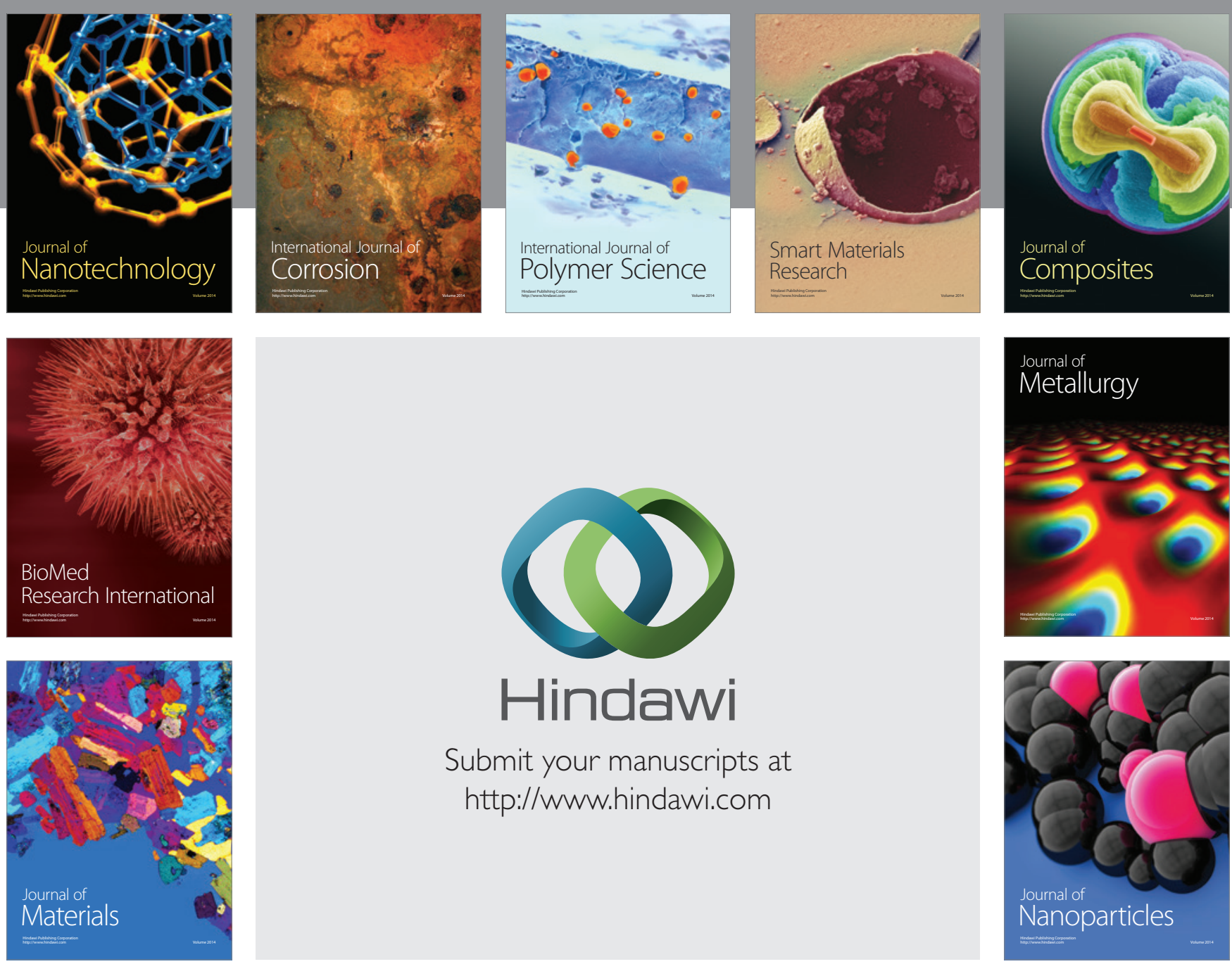

Submit your manuscripts at http://www.hindawi.com
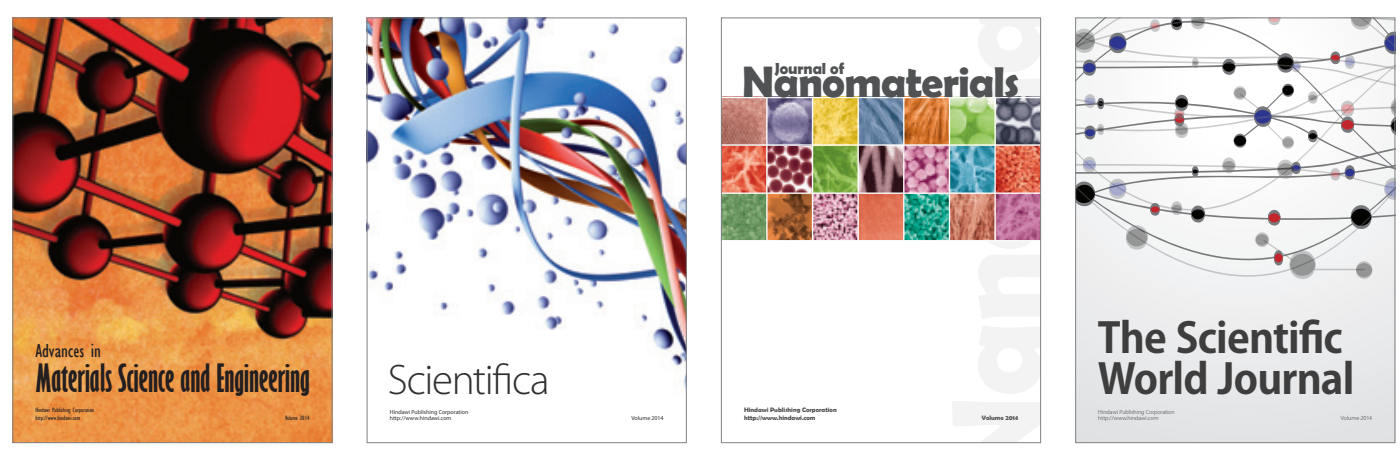

\section{The Scientific World Journal}
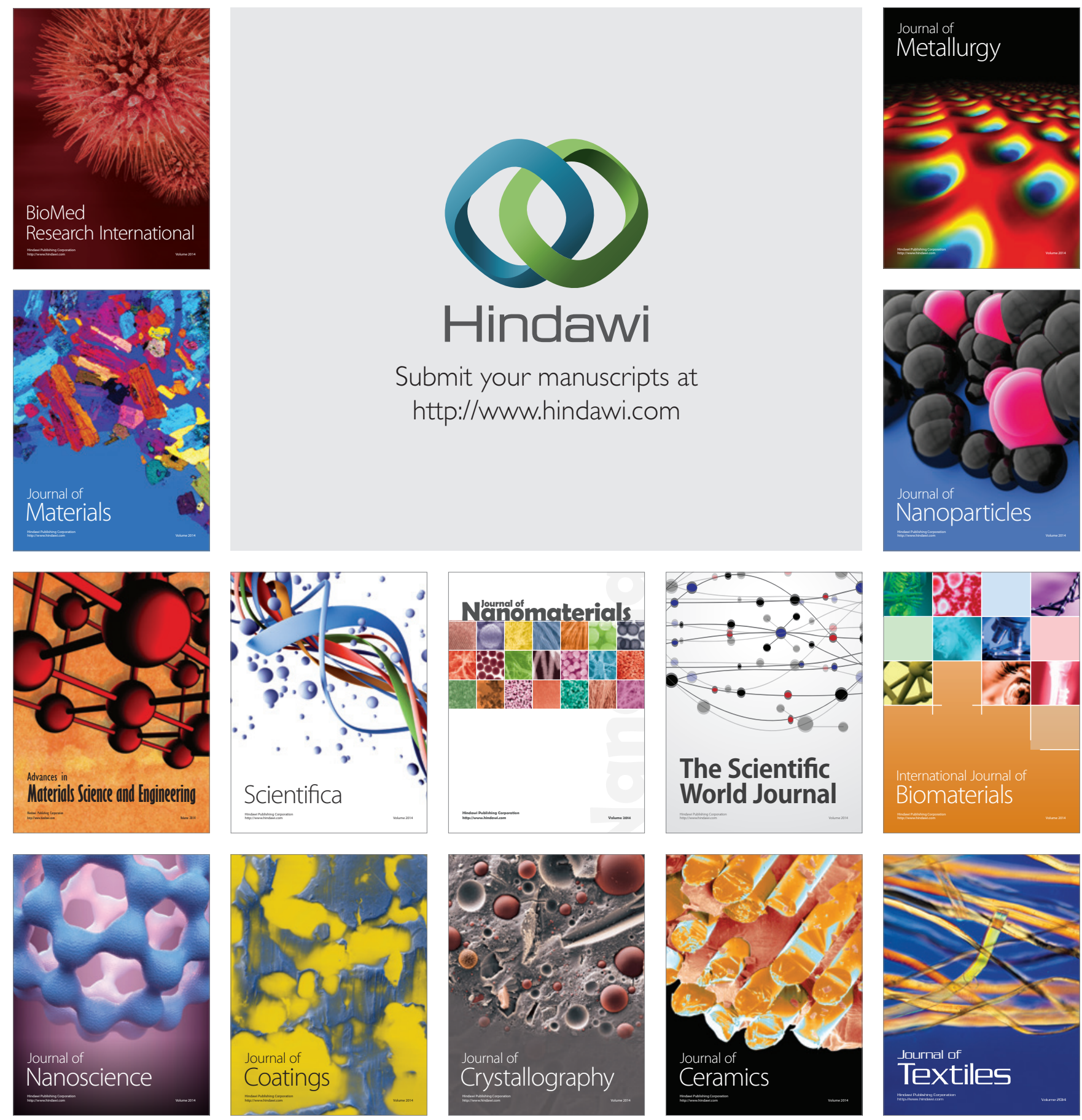